Revista Crítica de Ciências Sociais

de Ciênncias Sociais $\quad 101 \mid 2013$

Perspetivas interdisciplinares sobre consumo e crédito

\title{
Graeber, David (2011), Debt: The First 5,000 Years
}

Hugo Miguel Pinto e Ana Rita Carvalho

\section{(2) OpenEdition \\ Journals}

Edição electrónica

URL: http://journals.openedition.org/rccs/5409

DOI: $10.4000 /$ rccs.5409

ISSN: 2182-7435

Editora

Centro de Estudos Sociais da Universidade de Coimbra

Edição impressa

Data de publição: 1 setembro 2013

Paginação: 157-159

ISSN: 0254-1106

Refêrencia eletrónica

Hugo Miguel Pinto e Ana Rita Carvalho, «Graeber, David (2011), Debt: The First 5,000 Years », Revista Crítica de Ciências Sociais [Online], 101 | 2013, posto online no dia 17 fevereiro 2014, consultado o 04 fevereiro 2021. URL: http://journals.openedition.org/rccs/5409; DOI: https://doi.org/10.4000/rccs. 5409

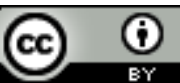




\section{Recensões}

\section{Streeck, Wolfgang (2013), Tempo comprado - A crise adiada do capitalismo democrático. Coimbra: Actual, 293 pp.}

Publicado originalmente na Alemanha, em 2013, e rapidamente traduzido para português, este é um notável livro de "macrossociologia" ou de "economia política”, enquanto história racionalizada da evolução do capitalismo nos últimos quarenta anos. O sociólogo alemão Wolfgang Streeck, diretor do prestigiado Instituto Max Planck para o Estudo das Sociedades, em Colónia, desenvolve em livro as suas Lições Adorno, organizadas pelo Instituto de Estudos Sociais de Frankfurt em homenagem a um dos seus fundadores, Theodor Adorno. Entre outros temas, o livro analisa criticamente o destino de algumas das teses que, precisamente na esteira da Escola de Frankfurt, diagnosticaram, sobretudo entre os anos sessenta e setenta, a crise de legitimidade de uma economia capitalista avançada, supostamente domada por cima do ponto de vista técnico, mas ética e culturalmente contestada por baixo. Daí até à crítica à possibilidade de uma democracia pós-nacional com poder redistributivo na União Europeia, na atualidade, Streeck constrói um percurso organizado em três densas, mas claras lições - "da crise de legitimidade à crise orçamental", "reforma neoliberal" e "neoliberalismo na Europa" -, enquadradas por uma introdução e conclusão substantivas.

O seu ponto de partida é a desvalorização e subestimação, em alguma teoria crítica, do papel crucial dos capitalistas e dos mercados, sobretudo financeiros, da base material do conflito social e das classes com as suas frações, lutas e alianças. Assim, os que desligam as supostas dinâmicas político-culturais e comunicacionais das bases materiais dos capitalismos realmente existentes, que, pelo menos em última instancia, lhes subjazem, cometem erros intelectuais e políticos custosos. Neste contexto, Streeck defende a validade de um projeto intelectual realista, baseado em pressupostos inspirados na economia política marxista, mas também em tradições intelectuais que com ela dialogaram, como o institucionalismo crítico de Karl Polanyi: "Elaborar uma teoria macrossociológica da crise [financeira e orçamental das democracias capitalistas ricas] e uma teoria social da democracia sem referência à economia enquanto atividade político-social tem de parecer absolutamente errado, tal como o pareceria qualquer conceção de economia na política e sociedade que ignorasse a sua organização capitalista atual” (p. 20). Confirma-se que, para estudar o capitalismo e as suas configurações histórico-espaciais concretas, é preciso transgredir as barreiras disciplinares, já que no seio das abordagens mais disciplinadas, o capitalismo se tornou num objeto que tende a primar pela ausência, quer seja por razões metodológicas, quer seja por razões de policiamento e de conveniência político-ideológica.

Pelo contrário, neste livro as forças sociais que suportaram e suportam o capitalismo, em geral, e as que suportaram e suportam a sua declinação neoliberal, emergente a partir da década de setenta, em particular, têm primazia na análise. É assim dada especial atenção aos recursos institucionais, económico-financeiros, políticos e ideológicos mobilizados para, 
em capitalismos com democracias cada vez mais limitadas, se conseguir um necessário consenso, mais ou menos passivo, mais ou menos ativo, das classes sociais subalternas. Este consenso era tanto mais indispensável quanto as classes subalternas tinham conseguido no pós-guerra ganhos relevantes, traduzidos numa certa incrustação social-democrata de um capitalismo obrigado a concessões relevantes no campo regulatório e redistributivo, implicando processos combinados de desglobalização e de desmercadorização, entretanto largamente revertidos. É também sobre essa reversão e regressão e sobre as suas contradições que este livro se debruça, sendo que a expressão "tempo comprado" revela o fio condutor da resposta a uma das questões sociais mais difíceis do ponto de vista intelectual e político: como é que as classes subalternas aceitaram o capitalismo transformado pela neoliberalização, com o seu cortejo de desemprego, fragilização, ainda que lenta, dos Estados sociais, sobretudo na sua dimensão de provisão pública de bens e serviços sociais e de regulamentação das relações laborais, e consequente aumento generalizado das desigualdades de rendimento e de riqueza?

Assim, e para lá da análise de alguns dos mecanismos disciplinadores clássicos, de que as frações dominantes do capital lançaram mão ou de que se aproveitaram para contrariar e reverter a sua perda de poder e de lucros, visível de forma dramática nos anos setenta, - do desemprego elevado, que fragiliza a ação coletiva dos trabalhadores, à multiplicação de hipóteses de fuga e de "greve de investimento" por via da construção da globalização -, Streeck indica-nos outros mecanismos assentes na "compra" da lealdade de frações da classe operária e das classes intermédias em muitos países desenvolvidos, contendo o conflito social latente. Estes mecanismos de integração assentaram mais concretamente na "compra de tempo" porque passaram pela mobilização sem precedentes da "instituição misteriosa da modernidade capitalista”, o dinheiro. Significa isto que foi sobretudo por via do acesso ao consumo a crédito que amplos segmentos das massas acabaram por aceitar transformações regressivas, como foi também por via do acesso ao crédito que os Estados as geriram. O tratamento da moeda, do crédito, de resto breve, é o ponto menos conseguido do livro. Este parece partilhar um diagnóstico equivocado, segundo o qual a inflação elevada teria tendencialmente origens monetárias, isto é, proveniência nas ações dos bancos centrais.

Streeck constrói uma cronologia, por referência inicial mais ou menos explícita aos desenvolvimentos da economia norte-americana, com algumas adaptações às economias europeias centrais, onde o processo de financeirização teria assentado, inicialmente, em políticas monetárias geradoras de inflação elevada, de resto rapidamente trocadas, no final dos anos setenta, por políticas ortodoxas centradas no combate à inflação. Seguiu-se o aumento da dívida pública que foi, nos anos oitenta, essencial para a expansão dos mercados financeiros cada vez mais liberalizados em contexto de desaceleração do crescimento e, fundamentalmente, na dívida privada a partir daí. Streeck estaria em terreno mais sólido se tivesse retirado o processo inflacionário desta história, dado que este ocorre num período anterior à financeirização, que teve nas políticas de combate à inflação um dos seus motores. A financeirização é o processo material a que o neoliberalismo dá cobertura ideológica. O capital, sobretudo na sua forma financeira, tem horror à inflação, que reduz os seus rendimentos e beneficia os devedores. Seja como for, o processo político de aumento do peso do setor financeiro 
inseriu os Estados e amplos segmentos da população nos circuitos dos mercados financeiros, mascarando problemas de procura, alimentando uma cada vez mais agressiva e atomizada sociedade de consumo e de endividamento, por um lado, e incrementando a participação de segmentos politicamente relevantes $\mathrm{da}$ população na especulação e no rentismo financeiros, por outro, sendo estas camadas que detêm mais voz política num contexto de apatia e descrença política generalizadas entre as classes populares. Estes processos de financeirização e de mercadorização erodiram identidades políticas e sociais contra-hegemónicas e deram "cobertura política" para uma transição estrutural que assentou na "desdemocratização do capitalismo através da deseconomização da democracia” (p. 30). Isto quer dizer que a reconfiguração dos Estados operada pelo neoliberalismo assentou num progressivo bloqueamento da capacidade democrática para moldar o curso das economias. No fundo, o "povo do Estado", aquele que depende do acervo dos direitos e serviços sociais, tornou-se cada vez mais impotente perante o "povo dos mercados”, isto para usar uma útil dicotomia forjada por Streeck. Esta complementa a clássica trilogia da "saída, voz e lealdade" do economista político Albert Hirschman. A impotência democrática foi também o resultado de um lento mas eficaz processo de mudança institucional - da tal expansão dos mercados financeiros à entrega da condução da política monetária a bancos centrais ditos independentes $\mathrm{e}$ que não respondem perante a democracia, passando por um Estado fiscal cada vez mais regressivo, até porque com cada vez menos condições institucionais e político-ideológicas para taxar a finança e os altos rendimentos.

Neste quadro estrutural, a crise de 2007-08 veio revelar como os processos e mecanismos atrás referidos contiveram, na dupla aceção da palavra, a crise de um capitalismo cada vez mais divorciado da democracia. Aqui chegados, Streeck coloca-nos em melhores condições não só para compreender a longa gestação da atual crise, mas sobretudo para nos mostrar como o reforço da lógica neoliberal que a acompanha não deve surpreender ninguém, dado o lastro político e institucional com múltiplas escalas, nacional e supranacional, que o bloco social neoliberal, o tal "povo dos mercados”, acumulou. Uma das expressões deste lastro é precisamente o "Estado endividado", fruto da perda de poderes fiscais, da capacidade da finança para socializar os custos da crise ou da interdependência entre dívida privada e dívida pública, num contexto em que o esforço descoordenado dos privados para reduzir a sua dívida provoca, por via da crise de procura, rombos nas finanças públicas. Streeck indica-nos de forma competente que é a fraqueza seletiva dos Estados, e não qualquer disfunção democrática traduzida numa suposta inflação de exigências sociais, que explica estruturalmente parte dos atuais níveis de endividamento público em muitos países. Crucialmente, a política do endividamento, com escala internacional, tem tradução numa opaca diplomacia financeira, onde se cruzam instituições internacionais, frações do capital que operam nessa escala e Estados com distintas posições, credoras e devedoras, dada a lógica do chamado desenvolvimento desigual e combinado, reeditada pelo capitalismo neoliberal. $\mathrm{O}$ endividamento internacional constitui um mecanismo poderoso de afirmação de formas de exercício de autoridade política pós-democráticas, dado que o "povo do Estado" democrático não consegue operar numa escala dotada de um forte viés neoliberal.

Streeck conduz-nos, então, na sua terceira e última lição, a um dos centros mais concretos da crise do casamento do 
capitalismo com a democracia, com a voz popular: a União Europeia, em geral, e a Zona Euro, em particular. Este capítulo contém uma das mais lúcidas análises sobre a natureza da integração europeia disponíveis em português, expondo de forma clara a sua natureza irremediavelmente neoliberal e pós-democrática e os mecanismos que sustentam todas as ilusões europeístas, ainda tão influentes entre as elites intelectuais, políticas e económicas, em especial nesta periferia europeia.

Beneficiando do intenso trabalho coletivo de investigação do Instituto que dirige sobre este tema, Streeck começa por mobilizar a história das ideias, em particular as teses federalistas neoliberais de Friedrich Hayek, um dos pensadores do fundamentalismo de mercado e de uma "democracia limitada" no século XX. A apresentação das teses de Hayek serve para nos mostrar como a União Europeia é a expressão institucional mais acabada do neoliberalismo enquanto projeto de construção e expansão da disciplina de mercado, suportado por instituições sem escrutínio democrático - do Tribunal de Justiça Europeu ao Banco Central Europeu - e por regras do jogo que criam um colete-de-forças, o que apoda de "Estado de consolidação", que prende os Estados-nação e logo as democracias realmente existentes à austeridade permanente e a reformas estruturais de matriz neoliberal continuadas. A escala europeia é a escala política das frações mais extrovertidas do capital, dos credores, e as suas instituições estão bem calibradas para consolidar o poder do "povo dos mercados" sobre as classes populares. Sem financiamento monetário por parte dos seus bancos centrais, que reduza a dependência dos Estados face aos mercados financeiros; sem controlos de capitais, que reduzam a chantagem do capital que pode facilmente sair; e, ponto a que Streeck dá primacial importância, sem a possibilidade de desvalorizar a moeda, isto é, sem política cambial, tida como "uma espinha cravada na garganta do totalitarismo de um mercado único" (p. 265), as comunidades políticas nacionais, onde muitos cidadãos ainda sentem justificadamente que há um destino comum, ficam desprovidas das bases materiais de que é feita a soberania democrática. A desvalorização cambial é uma espinha cravada, até porque, na sua ausência, os ajustamentos fazem-se pela "desvalorização interna", ou seja, pela queda dos salários diretos e indiretos (as prestações sociais), um processo muito mais socialmente injusto e economicamente destrutivo.

Como Streeck enfatiza, isto não é um destino inexorável, fruto de inefáveis lógicas globais, mas sim o resultado de uma perversa construção política contra as nações, contra os povos, contra a democracia. A severidade socioeconómica deste processo é particularmente sentida hoje nas periferias europeias, estruturalmente prejudicadas por uma moeda forte e sem poder beneficiar de transferências significativas, dado o peso residual do orçamento europeu. De qualquer forma, Streeck é muito claro sobre as razões para a inexistência de uma União Europeia sem orçamento redistributivo digno desse nome, em que as regiões ricas financiariam maciçamente as regiões pobres, aguentando-as à tona. Com efeito, a Europa não é um Estado e não o será, até porque os povos não o desejam, o que significa que o federalismo só pode ser furtivo, clientelar e perverso, incapaz de mobilizar lealdades populares. $\mathrm{E}$, mesmo que os povos o desejassem, seria mais do que duvidoso que as transferências pudessem substituir com o mesmo sucesso a mobilização de instrumentos de política à escala nacional. Mas, infelizmente, como Streeck sublinha, nada nos diz que as alianças sociais que sustentam o Euro, e que na periferia incluem elites extrovertidas, as que gostam de moeda forte para 
viajar e importar bens de consumo mais ou menos conspícuos, não consigam manter um projeto que se aproxima cada vez mais de uma "operacionalização do modelo social hayekiano [anti-social-democrata] da ditadura de uma economia de mercado capitalista acima de qualquer correção democrática” (p. 252)

Embora opte por um forte pessimismo da inteligência e defenda que um cientista social não tem necessariamente de fornecer alternativas, até porque estas podem bem não existir, Streeck, num vislumbre de otimismo da vontade, para usar a distinção gramsciana, não deixa de depositar esperanças numa ainda demasiado vaga resistência dos povos a esta ditadura dos mercados. Esta terá de passar por uma desobediência dos devedores, implicando, entre outras medidas, o incumprimento da dívida e o desmantelamento do Euro. Isto se se quiser salvar a cooperação europeia e as democracias nacionais. A redescoberta europeia do espírito de Bretton-Woods, dos arranjos monetários flexíveis, articulando cooperação internacional e soberania nacional no campo monetário e financeiro, é uma das suas propostas. O ceticismo, fundado em boas razões, face a uma moeda que está a matar a Europa só pode ser social e democrata, só pode ser socialista. Se mais nenhum mérito tivesse, e tem muitos outros, este livro dá um corajoso contributo para inscrever esta perspetiva no debate público e na luta política, para dar voz aos "povos dos Estados".

João Rodrigues

\section{Graeber, David (2011), Debt: The First 5,000 Years. New York: Melville House Publishing, 534 pp.}

No seu livro Divida, os primeiros 5000 anos, o conceituado antropólogo David Graeber apresenta-nos uma crítica arreigada ao sistema económico mundial, traçando o perfil antropológico do surgimento do dinheiro, da dívida e dos significados que ambos foram adquirindo no decurso da história da humanidade. Ao traçar o seu perfil histórico, Graeber pretende sensibilizar o leitor para todo um conjunto de assunções normalmente tácitas, comumente aceites no meio económico, traçando paralelismos entre épocas, históricas e civilizações e alertando para as suas incongruências com o objetivo de conduzir o leitor ao questionamento e à reflexão sobre as implicações morais da dívida.

O tema principal e amplamente retratado de uma perspetiva antropológica centra-se em torno da dívida que, na análise de Graeber, é a unidade principal de compreensão da história do dinheiro, da economia de mercado, do desenvolvimento da própria humanidade e, em última análise, encerra a compreensão do destino da humanidade, tal como a conhecemos atualmente.

Ideologicamente questiona a proliferação de um sistema capitalista a uma escala mundial ao colocar em causa o seu primeiro e mais proeminente corolário: a assunção de que todos devemos pagar o que devemos. De um ponto de vista histórico, centrando-se nas dívidas dos países em vias de desenvolvimento, Graeber condena o capitalismo selvagem e questiona o fundamento do próprio sistema de dívida, ao considerar que o corolário principal do sistema capitalista é muito mais uma afirmação moral do que um princípio económico.

Graeber evidencia em vários momentos ao longo do seu livro que a forma como pensamos e perspetivamos a dívida, enquanto obrigação moral de reciprocidade entre 
pessoas ou entidades com dinheiro disponível, faz pouco sentido fora de uma economia de mercado. Durante milénios, as sociedades e os seus cidadãos encontraram formas alternativas e proativas de distribuir, consumir e prestar bens e serviços, de estabelecer relações empresariais e de subordinação profissional e laboral, através de complexas teias de reciprocidade e oferendas entre grupos de parentesco e sociais. Apesar da ampla fundamentação e análise antropológica, o autor, escusa-se, contudo, a traçar caminhos alternativos ajustados à atual realidade económica e social que possam vislumbrar-se enquanto soluções credíveis, social e moralmente aceitáveis, de partilha e relação económica. Ao longo da sua obra Graeber questiona, igualmente, de forma muito marcada o mito económico de que o dinheiro surgiu como forma de suplantar as dificuldades inerentes às sociedades que operavam em termos de trocas diretas. Aceitando que as bases da vida económica derivam, efetivamente, da natureza e necessidade humana de troca de produtos, aquisição de necessidades e disposição de excedentários, o autor questiona a plausibilidade da ideia amplamente difundida de economias assentes maioritariamente em trocas diretas. A propósito do que Graeber se refere enquanto mito económico, o autor sustenta que as trocas diretas não subsistiam exclusivamente com maior pendor e evidência no seio de uma mesma sociedade, mas antes entre sociedades mais distantes, ímpares ou mesmo inimigas com o registo antropológico dos mais diversos sistemas económicos a nível local. Deste modo, Graeber apresenta-nos uma visão complexificada do surgimento do dinheiro numa perspetiva mais ampla decorrente da guerra, violência, ostracização e repressão no que Graeber define como economia humana. Ao longo da obra, somos constantemente confrontados com as evidências antropológicas da importância que as relações humanas e a sua própria natureza detêm nas transações económicas. Neste sentido, o autor procura sair da esfera economicista e técnica para nos apresentar uma visão em que parece procurar vislumbrar nas relações humanas e sociais a génese da compreensão das crises económicas dos últimos anos e as revoluções que, mais uma vez, parecem começar a operar-se.

Argumentando que, ao contrário do que, porventura seria de supor, a dívida e os seus significados são muito anteriores ao conceito de dinheiro cunhado, Graeber sustenta que a dívida, mais do que uma premissa económica, encontra a sua génese e transformação na esfera das oferendas, da reciprocidade e da troca de presentes ou favores que, ao se tornarem identificáveis e quantificáveis, de forma nem sempre o mais objetiva, adquire um caráter moral que muitas vezes se encontra na origem de grandes conflitos armados e revoluções civilizacionais.

Neste sentido, Graeber refere inúmeros sistemas sociais nos quais o dinheiro, enquanto unidade económica quantificável, era pouco utilizado pelas pessoas para adquirirem os seus produtos de maior necessidade. Ao invés, as dívidas eram antes muitas vezes pagas através do serviço militar, favores sexuais ou até mesmo através de vidas humanas.

Antropologicamente, Graeber fundamenta precisamente a dimensão humana e social que sempre circundou o dinheiro, perspetivando, na sua trajetória histórica, o desenvolvimento e a oscilação entre épocas marcadas pelo dinheiro físico, característico de períodos históricos marcados pela generalização da guerra, pelo caos social e tumulto governamental ou religioso, e épocas marcadas pelos sistemas de crédito virtual que tendem a ser dominantes em períodos de alguma paz social, 
assente em redes de confiança mútua. Deste tema, tratam precisamente os últimos cinco capítulos do livro de Graeber, ao evidenciar uma grande profundidade de análise antropológica e história universal. Graeber salienta, ainda, que nas fases ou nos impérios nos quais o dinheiro físico predominava, as trocas eram efetuadas através de pedaços de metal, com valor relativamente arbitrário, ou de escravos numa sociedade liderada por forte pendor político-governamental, ao invés das fases em que predominava o crédito virtual, marcadas pela fragmentação da autoridade e poder político em que imperavam a vassalagem, a servidão ou os juramentos de obrigação, o dízimo e o tributo.

Historicamente, Graeber identifica duas correntes distintas ao nível civilizacional que estabeleceram distintas conceções dos tributos fixos. Por um lado, o sistema egípcio em que o Estado definia de modo quantificável o tributo ou imposto a pagar ao próprio Estado. Por outro lado, o sistema mesopotâmico, alicerçado numa relação de tributos ou impostos a elites societais, como o clero ou mercadores, que quantificavam as relações anteriores de oferendas, estabelecendo um sistema de dívida social a classes proeminentes. Ao longo de toda a obra, o autor parece fazer o constante exercício de conduzir o leitor a traçar paralelismos entre as evidências históricas e antropológicas que vai traçando e a realidade económica e social com que nos deparamos atualmente. Graeber procura, deste modo, trazer alguma clarividência, definindo que a realidade atual é apenas travestida de novas circunstâncias, permanecendo os significados e os mecanismos transformadores relativamente idênticos aos que a antropologia nos permite conhecer, estudar e analisar.

Perante o atual momento e contexto económico e social, o livro de Graeber constituiu-se enquanto obra de extrema atualidade e cognitivamente inquietante, que procura conduzir-nos a refletir sobre a obrigação moral inerente a um sistema de dívida, sendo que a questão do que constitui uma dívida, quem deve pagá-la, e como deve ser reembolsada, deverá constituir-se enquanto um processo contínuo de revisão. Ao estabelecer a centralidade da sua obra em torno da importância e omnipresença do conceito de dívida nas relações sociais humanas em todas as sociedades e momentos históricos, Graeber advoga a favor de um modelo de comportamento económico, no qual a partilha, mais do que a reciprocidade, deveria perspetivar-se enquanto o principal corolário da política económica a nível mundial. Este mesmo sentimento parece ter tido o seu expoente máximo em movimentos sociais, como o "Ocuppy Wall Street" ou as manifestações sociais no âmbito da crise das dívidas soberanas em alguns países no velho continente. Contudo, a maior crítica que se pode fazer a Graeber é a de que tem o mérito de identificar e nos apresentar um conjunto impressionante de evidências do caminho que a sociedade traçou até chegar ao modelo económico e social atual e a lacuna de não nos indicar, claramente, soluções ou indicações de como poderemos progredir de agora em diante, num mundo globalizado e uma realidade com características e desafios seguramente distintos e particulares.

Hugo Miguel Pinto Ana Rita Carvalbo 


\section{lyengar, Sheena (2012), The Art of Choosing. London: Abbacus, 336 pp. [3. ${ }^{\text {a ed. }}$ ]}

O livro $A$ arte de escolher dispõe de um prólogo titulado "Past is Prologue" a que se seguem sete capítulos e um epílogo, rematados com um posfácio para a edição paperback aqui recenseada. Capítulo 1 - "The Call of the Wild"; Capítulo 2 - "A Strange in Strange Lands"; Capítulo 3 - "The Song of Myself"; Capítulo 4 - "Senses and Sensibility"; Capítulo 5 - "I, Robot?"; Capítulo 6 - "Lord of the Things"; Capítulo 7 - "And Then There Were None". Para além deste núcleo e de seis páginas de agradecimentos, o livro oferece ainda notas de apoio à leitura de cada capítulo que, não sendo remetidas do texto, evitam o vaivém que a sua leitura na própria página ou no fim implica, e descrevem os factos ou histórias "inspiradoras" dos conceitos, problemas e investigações, ou sinalizam e comentam alguma da bibliografia que é explícita ou implicitamente referida em cada capítulo. Por fim, o livro dispõe de um profuso índice remissivo que permitirá revisitações "guiadas" dos temas que nos capítulos ocorrem, por vezes no meio de "narrativas" de cariz pessoal ou jornalístico que poderiam, por essa razão, perder a referência ao interesse explicativo a que estão associadas.

Livros que ostentam no título "A arte de...", como o que aqui se apresenta, podem não passar de um receituário para lidar com o problema que tratam sob uma fórmula de "autoajuda", o que muitas vezes ocorre em livros de divulgação para o grande público, especialmente quando se trata de psicologia. Considere-se, pois, esta frase: "Equilibrar esperanças, desejos e a apreciação das possibilidades avaliando as limitações lucidamente: esta é arte de escolher.” (p. 277). Na verdade esta é a última frase do livro. Aqueles que gostam de dar um "salto" ao fim para, como nos livros policiais, confirmar a culpa do mordomo, poderão ficar com a impressão de que se trata realmente de um manual de autoajuda que termina com uma frase a um tempo trivial e opaca. Se desistirem da leitura com base nas opacidade e trivialidade da mesma, perderão a oportunidade de colher os elementos concretos e explícitos contidos em "esperança", "desejo", "possibilidades", "avaliação", "lucidez" e "limitações" que compõem a frase. O problema adensa-se se atentarmos agora noutra frase: "Fazemos escolhas e na volta somos feitos delas. A ciência pode ajudar a tornar-nos decisores mais capacitados, mas no seu âmago, a escolha permanece uma arte." (p. 268). Talvez agora o desejo de conhecer o fim da história de antemão se revele menos provável, embora a frase esteja também na parte final do livro. Mas, no caso de acontecer, antecipando o final, o leitor poderá formar a impressão de que algo mais ocorre neste livro. Talvez este seja o sentido que "arte" ali assume: o que escapa à lente do cânone científico, revelando os limites que esse olhar impõe ao tema da escolha, expõe outras linhas e elementos que, permitindo capturar a substância do tema, se constituem numa "arte de escolher". A arte pode ser vista, assim, mais como um caminho de superação da frustração a que o objeto condena na sua interpelação científica, do que uma via natural de "figuração", "narrativa" ou "receituário" da decisão.

A sugestão que o título do livro de Sheena Iyengar avança encontra um sinal seu na afirmação de que "'Escolha' pode significar tantas coisas diferentes e o seu estudo abordado de modos tão distintos que um livro não pode conter a sua completude." (p. xii), ao qual se junta o truísmo de que a escolha perpassa por todo um espectro 
de ação que vai "do trivial à transformação da vida” (p. xiii).

A escolha estará, pois, por todo o lado e levanta de antemão a suspeita de que, por essa mesma razão, a determinação do que é a escolha seja ela mesma elusiva face ao poder de fundamentação lógico-matemático ou da observação laboratorial ou de campo. Disso mesmo é testemunha a breve história da decisão a partir da publicação da Teoria dos jogos e comportamento económico de von Neumann $\&$ Morgenstern $\left(1953^{1}\right)$, que viu acentuar-se o declínio lento mas firme da sua premissa racional normativa (maximização da utilidade esperada), a par da crescente adoção dos elementos descritivos, decorrentes de premissas inaugurais das ciências sociais e sustentados em crescente evidência de anomalias à luz do paradigma da racionalidade laplaciana (Gigerenzer, 2008²).

No posfácio em que Iyengar faz um resumo inteligente da obra, não repetidor do "essencial" de cada capítulo, procede-se a uma alusão à receção pública das primeiras edições do livro, que se caracteriza pela perplexidade dos leitores que se manifestam "um pouco esmagados pela complexidade da escolha e pela enorme quantidade de informação.” (p. 269). Quanto a nós, tal perplexidade não dependerá verdadeiramente da escrita, por vezes de uma fluidez e clareza invejáveis, num registo pessoal, pontuado por referências à literatura universal, à investigação científica ou à vida simples do dia a dia. Porventura decorrerá antes da natureza intrínseca do objeto "escolha", que insistentemente surge como refratário a uma definição única.

Não obstante o estilo e os seus efeitos quanto a uma definição prescritiva de "escolha", uma vez lido por inteiro, o livro servirá bem o leitor pela competente descrição do estado da arte, essencialmente do ponto de vista da biologia e da psicologia social e intercultural, apoiado em notas a cada capítulo, já acima referidas. Afinal, a perplexidade dos leitores será mais um sinal da competência da descrição (insistimos de leitura agradável e não muito exigente) que parece conseguir transmitir a mais óbvia interpretação do que hoje se sabe sobre escolha e decisão no campo científico, abstendo-se no mesmo passo de assinalar "o" caminho, seguindo inclusivamente, por vezes, um tom provocatório pelo caráter dilemático da exposição, e fugindo assim a qualquer tentação de estabelecer receitas prontas a usar.

Mas este livro acrescenta ainda outro ponto de interesse: Iyengar discorre sobre temas centrais da nossa vida atual (e.g. consumismo, tolerância, globalização, religião) que consegue fazer girar em torno da escolha ou do escolher, o que funciona como um magneto que tudo atrai na vida individual, grupal ou em sociedade.

Antes, porém, é importante sublinhar que, do ponto de vista da psicologia, "A arte de escolher" percorre os themata de onde atualmente emergem as principais discussões em torno da decisão e da escolha. Não envereda, claro está, por discussões académicas sobre teorias normativas, prescritivas e descritivas da decisão, mas remete no caso das últimas para a evidência e interpretação científicas, por vezes problemáticas e não definitivas, que permitem traçar os contornos afetivos, cognitivos, motivacionais, culturais e políticos que enformam as escolhas do dia a dia, como as de longo prazo. Bom exemplo disso é a sequência que Iyengar consegue imprimir no livro, começando na noção da escolha

\footnotetext{
${ }^{1}$ von Neumann; J. Morgenstern, O. (1953), Theory of Games and Economic Behavior. Princeton, NJ: Princeton University Press [3. ${ }^{a}$ ed.]

${ }^{2}$ Gigerenzer, G. (2008), Rationality for Mortals. New York: Oxford University Press.
} 
como instintiva ou consciente e livre (situações extremas de vida ou morte de animais e seres humanos), seguindo para as condições individuais intrínsecas e extrínsecas. E daqui decorre que, neste jogo de condicionantes internas e externas, que podem ou não ser extremas, a circunstância da escolha seja sempre determinada por uma perceção, mais ou menos verídica, quanto ao maior ou menor controlo que sobre ela detém aquele que escolhe (uma vez mais ser humano ou animal). Este desenvolvimento vai adensando o problema da escolha, revelando uma tessitura para a qual todos estes fatores contribuem de forma desigual.

A autora parte de uma definição de decisão ou escolha que, no mundo ocidental, é familiar e remete para o livre arbítrio e para o poder de controlo e de formação de identidade individuais e, em última análise da felicidade (o “American Dream”). Ilustração interessante e eloquente é a da lista de escolhas feitas ao longo de um dia inteiro por um grupo de estudantes norte-americanos a viver em Tóquio, que revelam que qualquer ato mais ou menos automático, habitual ou trivial era considerado uma escolha (no sentido de deliberação) por parte de um sujeito consciente, determinado a cumprir um plano. As listas equivalentes feitas por alunos japoneses com o mesmo propósito correspondiam a folhas quase em branco. Muitas comparações interculturais são descritas de forma anedótica ou com evidência científica, resultando na fragilização da conceção familiar de escolha como dependendo exclusivamente de uma "vontade" individual e consciente. A autora discorre sobre como estas diferentes experiências subjetivas (na verdade também coletiva e culturalmente determinadas) implicam vivências distintas da cidadania e da ética. Um outro ponto de realce neste livro é o da questão da abundância de escolhas que somos obrigados a contemplar na organização social atual (e.g. consumo, saúde, finanças) e da abundância de opções dentro de uma mesma escolha. É o caso do questionário realizado por Iyengar em países do Leste da Europa, pouco tempo após a queda do Muro de Berlim (Alemanha, Polónia, Ucrânia, Rússia), em que cidadãos desses países se referem a uma opção entre sete marcas de refrigerantes (Coca-Cola, Pepsi, etc.) como uma escolha simples entre beber/não beber refrigerante. A edição dos elementos da própria estrutura ou arquitetura da escolha parece determinada por uma vivência em que as marcas não são um atributo a dar atenção, alterando a própria natureza da escolha. Mas a esta questão intercultural acresce uma outra, mais funda, sobre o valor da variedade de escolha, pelo menos em território dos EUA, e que está intimamente associada à liberdade de escolha (mas poderia de forma algo mitigada ser também na Europa Ocidental). Recorrendo à série "The Simpsons", em que o mercado de Springfield, chamado Monstromart, tem como lema a frase "Onde comprar é uma desconcertante provação" (p. 206), Iyengar consegue resumir o problema da escolha - especialmente no consumo: ao ver em muitas opções de escolha uma vantagem, podemos estar a reduzir a possibilidade de bem escolher devido a limitações cognitivas (de cálculo, de memória, de perceção, conduzindo à confusão e fadiga) e afetivas (desapontamento e arrependimento associados à escolha feita nessas condições), independentemente do fator motivacional que, em primeiro lugar, determinou desejo ou a necessidade de consumo. A pesquisa que tornou Iyengar famosa na área do marketing e da psicologia da decisão é precisamente aquela em que o fator número (variedade) de opções é manipulado com consequências contraintuitivas (capítulos 5 e 6). Se condescendemos que ter muitas 
opções é equivalente a uma condição para o exercício de liberdade de escolha, não damos conta de que nem sempre saímos mais contentes com a decisão tomada, como seria de esperar, como podemos inclusive sentir mais felicidade escolhendo num contexto em que a quantidade de opções é menor.

Por fim, referimo-nos a dois exemplos impressivos pela mescla de implicações que escolhas aparentemente privadas (consideradas individualmente ou em família) podem ter com consequências muito relevantes do ponto de vista ético, social e político. É o caso da descrição que Iyengar faz de escolhas como são as de "desligar" a máquina de um paciente (uma criança) em suporte de vida artificial ou do suicídio na terceira idade. As dimensões ética e técnica (de descrição dos processos e seus efeitos nos decisores) associadas a elementos de perceção e avaliação sob quadros culturais distintos, transmitem o sentido poderoso que a escolha assume nas nossas vidas seja para glosar o caráter individual ou coletivo da escolha, seja para salientar a sua dificuldade intrínseca. No primeiro caso, trata-se da comparação intercultural (EUA/França) sobre a responsabilidade em escolhas reais que consistem em manter ligado ou fazer desligar o suporte artificial de vida de uma criança que terá sempre, mesmo que mantida viva, profundas lesões cerebrais numa condição de total dependência. A delegação da escolha nos médicos, como sucede num caso em França, ao contrário do que acontece num caso equivalente nos EUA em que a decisão e responsabilidade são exigidas aos pais, revela-se para estes últimos como um momento insuperável e originador de sentimentos de culpa inultrapassáveis. Embora esta experiência seja também difícil e marcante para os pais franceses, estes mostram-se mais capazes de lidar com a perda e motivados para enfrentar a vida.

O segundo caso, relativo a suicídio/ /eutanásia voluntário/a, é o da escritora Jane Aiken Hodge, que decidiu e planeou suicidar-se aos 91 anos de idade, solitariamente e em segredo (armazenou durante anos os comprimidos necessários para o efeito), não obstante não ter, para a idade, qualquer problema de saúde "fatal" ou não controlado. Fê-lo, contudo, sem incorrer em qualquer delegação de responsabilidades inerentes a quem eventualmente estivesse ligado à assistência do seu suicídio. A força desta evidência (casuística neste último caso ou quasi-experimental no primeiro) é essencialmente problematizadora, lembrando que, na prática, tais decisões e escolhas são feitas efetivamente e, tal como os animais ou homens em situações extremas, a perceção de que controlamos a situação e, por isso, decidimos voluntariamente, assume intensidades e formas diversas, fazendo justiça à necessidade de aceitar que "escolher é uma arte” no sentido que a autora em várias instâncias do livro sugere.

Miguel Oliveira

\section{Olen, Helaine (2012), Pound Foolish: Exposing the Dark Side of the Personal Finance Industry. New York: Portfolio Penguin, 292 pp.}

Nas últimas décadas, temos vindo a assistir a transformações socioeconómicas profundas que têm conduzido a uma crescente participação das famílias nos mercados financeiros. Com maior expressão nas economias capitalistas mais desenvolvidas, como os Estados Unidos da América e o Reino Unido, observa-se um crescente 
papel do setor financeiro na mediação da provisão pública, em resultado da gradual retirada do Estado das suas funções sociais, forçando as famílias a recorrer a este setor para aceder a bens e serviços outrora providenciados pelo Estado como, por exemplo, nas áreas da educação, saúde e pensões. Esta tendência tem sido também sustentada pela degradação socioeconómica decorrente da estagnação salarial, da deterioração das condições laborais e da desigualdade na distribuição de rendimentos. Porém, as famílias também ficaram mais expostas às flutuações do ciclo económico, como ficou bem patente com a crise financeira internacional de 2007-08, que delapidou as poupanças entretanto investidas em fundos de pensões e causou a desvalorização generalizada das habitações compradas a crédito.

A severidade das consequências individuais e coletivas da crise criaram o contexto adequado para o florescimento da literatura de autoajuda financeira, que também já vai percorrendo o seu caminho em Portugal. É neste ambiente de extraordinário crescimento do setor financeiro e de crescente fragilidade financeira das famílias que o livro Pound Foolish: Exposing the Dark Side of the Personal Finance Industry da jornalista Helaine Olen adquire particular interesse.

Após uma breve introdução, o primeiro capítulo, intitulado "What Hath Sylvia Wrought?" remete o leitor para o período da grande depressão nos EUA e apresenta-nos Sylvia Feldman, a precursora das finanças pessoais. O segundo capítulo, "The Tao of Suze", e o terceiro, "The Latte is a Lie", relatam a emergência de um novo mercado editorial e os mitos propagados por dois influentes gurus financeiros, Suze Orman e David Back, respetivamente. Os restantes 6 capítulos focam-se sobretudo nos produtos e na cultura da indústria financeira. O capítulo 4 trata o complexo plano de pensões privado, os chamados 401(k), e a cultura de comissões do setor financeiro é exposta no capítulo 5. Já o capítulo 6 desconstrói o mito da existência do investimento perfeito, enquanto o capítulo 7 explora a literatura de autoajuda dirigida às mulheres. $O$ capítulo 8 debruça-se sobre os mitos que circundam o investimento no mercado imobiliário e, por fim, o capítulo 9 critica a opção política da educação financeira como solução para as más decisões financeiras dos consumidores. $\mathrm{Na}$ conclusão a autora apresenta algumas propostas para a resolução das questões abordadas ao longo do livro. No final do livro, encontram-se algumas notas que permite uma leitura fluente e ritmada dos capítulos.

Helaine Olen, autora da coluna "Money Makeover" no diário Los Angeles Times, e focando-se na realidade norte-americana, analisa criticamente a indústria da autoajuda financeira, estabelecendo uma ligação estreita entre, por um lado, o desmantelamento dos sistemas de provisão públicos que crescentemente transferem para o indivíduo a responsabilidade pela sua segurança financeira futura e, por outro lado, o movimento das finanças pessoais - acarinhado pela literatura da autoajuda - que reforça e legitima este processo de individualização da proteção social. Um exemplo paradigmático destas transformações diz respeito aos planos de poupança-reforma $401(\mathrm{k})$, que visam a transferência de parte do salário do trabalhador para fundos de investimento, o que se traduz num aumento do risco individual, já que o valor da reforma passa a depender do funcionamento volátil dos mercados financeiros. Por outro lado, estes planos implicam novas decisões financeiras, uma vez que compete ao indivíduo decidir quanto e em que aplicações financeiras investir, tornando imperioso um aumento da capacitação financeira, que a literatura de autoajuda procura colmatar. 
Centrando-se na emergência de celebridades na área financeira com presença diária na comunicação social norte-americana, como David Bach, Robert Kiyosaki e Suze Orman, a autora chama a atenção para o ridículo das soluções apresentadas, como a promessa de enriquecimento através de pequenas poupanças diárias, ao mesmo tempo que sublinha os erros grosseiros, a fraude disfarçada, os conflitos de interesse e os efeitos perversos desta literatura. Alguns exemplos bastam para a autora ilustrar a perversidade e a inconsequência destas iniciativas. É o caso do que ficou conhecido como o "latte factor", conselho proposto por David Back (1999) em Smart Women Finish Rich, o qual sugere que a aplicação financeira de pequenas poupanças diárias decorrentes da redução do consumo de frivolidades, como tomar café na famosa cadeia Starbucks, gerará retornos extraordinários. $\mathrm{O}$ autor defende que uma poupança diária de 5 dólares permitirá um encaixe de 2 milhões de dólares no momento da reforma. Contudo, este cálculo padece de vários erros, destacando-se o valor irrealista da taxa de retorno de $11 \%$ utilizada nos seus cálculos.

Outras recomendações terão até alimentado a bolha imobiliária norte-americana, aliciando o investimento no mercado imobiliário com a promessa de retornos "de $100 \%$ até ao infinito", considerando-se que "investimentos de 5000 dólares cedo se transformam em lucros de 1 milhão de dólares ou mais" (Kiyosaki, 2000, em Rich $\mathrm{Dad}$, Poor Dad). Outros autores foram mais longe, recomendando este investimento independentemente das condições socioeconómicas dos investidores, e referindo explicitamente que "não é preciso muito dinheiro para fazer um pagamento inicial de uma casa", nem tão-pouco "ter um bom crédito para comprar uma casa", devendo-se "comprar uma casa mesmo quando se tem dívidas no cartão de crédito" (Bach, 2006, em The Automatic Millionaire Homeowner). Como é hoje sobejamente conhecido, os empréstimos subprime, isto é, o crédito hipotecário de menor qualidade e que é sobretudo dirigido às camadas da população de mais baixos rendimentos, o qual cresceu de $9 \%$ para $40 \%$ entre 2001 e 2006, culminou no incumprimento em larga escala quando o valor das casas já não conseguia cobrir os empréstimos contraídos em resultado da desvalorização da habitação e da subida das taxas de juro.

No entender de Olen, existe um denominador comum a todas as propostas: todos os conselhos veiculados implicam o recurso à finança como forma de resolução dos problemas financeiros das famílias, quer seja através do recurso ao crédito quer ao investimento financeiro. E em alguns casos há gritantes conflitos de interesse, especialmente quando os conselhos financeiros promovem os interesses de grupos económicos particulares. Suze Orman chega mesmo a participar na campanha publicitária da General Motors para promover a compra a crédito de carros novos, tendo antes condenado a contração de dívida para este efeito e defendido, em alternativa, a compra de carros usados. No entanto, Orman, como lembra Helaine Olen, não se absteve de responsabilizar os consumidores pela crise financeira de 2007-08, considerando que esta se deveu à generalização de padrões de consumo excessivo.

Para além da promoção dos interesses da finança, apresentando produtos e serviços financeiros como soluções para os mais variados problemas, esta literatura veicula os valores de uma sociedade individualista que legitima esses mesmos interesses. Segundo Olen, a força motriz deste movimento é a responsabilização dos indivíduos pela sua situação financeira que assenta na ideia de que o sucesso ou 
insucesso financeiro depende exclusivamente da ambição e autodisciplina do indivíduo. Não é, por isso, de estranhar que em sociedades de matriz patriarcal, esta literatura encontre nas mulheres a sua população alvo. Com efeito, o sexo feminino é frequentemente retratado como sendo financeiramente inapto e tendo uma relação demasiado emocional com o dinheiro, o que justificará as suas eventuais dificuldades na gestão das finanças pessoais. Às mulheres é, assim, pedido que pensem e atuem no campo financeiro como um homem, que sejam mais racionais e assumam mais riscos no seu perfil de investimento.

Fica, pois, claro que fatores socioeconómicos, como a deterioração das condições de vida da classe média norte-americana e o crescimento das desigualdades, incluindo entre géneros, bem como o crescente peso económico e político da finança, não são sequer abordados por esta literatura.

Mas Olen não se limita a refletir criticamente sobre a literatura da autoajuda financeira e vai mais longe, debruçando-se sobre os programas de educação financeira que visam capacitar o consumidor para uma nova realidade em que a provisão do seu bem-estar passa cada vez mais pelo consumo de produtos e serviços financeiros. Questiona esta aposta promovida pelo regulador dos mercados financeiros e pela própria indústria financeira norte-americana, considerando que estas iniciativas estão condenadas a fracassar porque os problemas com que os consumidores estão confrontados, em resultado da retração do Estado social e da estagnação salarial, não se resolvem com literacia financeira. Pelo contrário, estes tendem a agravar-se porque, segundo Olen, a educação financeira mascara a necessidade de uma regulação mais apertada dos produtos financeiros e das suas práticas de comercialização.

No último capítulo, com o sugestivo título "We Need to Talk about Our Money", Olen chega a defender contestações semelhantes ao fenómeno do "Occupy Wall Street" como forma de promover as reformas preconizadas. Em entrevistas posteriores ao lançamento do livro insiste que a resolução dos problemas financeiros das famílias americanas passa pelo aumento do salário mínimo nacional, pela reformulação dos planos públicos de pensões e pela intervenção do governo no setor financeiro, pouco ou nada regulado. $\mathrm{Na}$ senda do jornalismo de investigação e, por isso, desprovido de uma ancoragem teórica capaz de expor os mecanismos que conduziram ao peso crescente da finança, e como esta se articula com a literatura de autoajuda financeira, este livro não deixa de expor com clareza os conflitos de interesse desta indústria e a natureza fraudulenta das soluções apresentadas, que legitimam a expansão do setor financeiro e a responsabilização do consumidor pelas consequências de decisões cujos resultados nunca são da sua inteira responsabilidade.

Vânia Costa 